\title{
Innovation and Competitive Intelligence in Business. A Bibliometric Analysis
}

\author{
Carlos de las Heras-Rosas *(D) and Juan Herrera *(D) \\ Department of Economics and Business Administration, Universidad de Málaga, 29071 Málaga, Spain \\ * Correspondence: chr@uma.es (C.d.1.H.-R.); juanherrera@uma.es (J.H.)
}

Citation: de las Heras-Rosas, Carlos, and Juan Herrera. 2021. Innovation and Competitive Intelligence in Business. A Bibliometric Analysis. International Journal of Financial Studies 9: 31. https://doi.org/ 10.3390/ijfs9020031

Academic Editor: Tihana Škrinjarić

Received: 24 March 2021

Accepted: 3 June 2021

Published: 10 June 2021

Publisher's Note: MDPI stays neutral with regard to jurisdictional claims in published maps and institutional affiliations.

Copyright: (c) 2021 by the authors. Licensee MDPI, Basel, Switzerland. This article is an open access article distributed under the terms and conditions of the Creative Commons Attribution (CC BY) license (https:/ / creativecommons.org/licenses/by/ $4.0 /)$.

\begin{abstract}
The business environment of today is complex and dynamic due to increasing global competition. The businessman needs to master and know all the information that has strategic value, and Competitive Intelligence is positioned as the most appropriate tool to achieve this goal. In recent decades, research and publications related to Competitive Intelligence have been increasing, although the military heritage of this field of research and the association with large corporations has meant that the literature is still at an early phase of development and specialisation. This paper analyses scientific articles on Competitive Intelligence from journals in the Web of Science database between 1985 and 2021. The main objective of this research has been to detect the topics that have been most related to Competitive Intelligence. The 589 papers analysed indicate that interest in this topic is relatively recent and that the most central topic in the sample is Innovation. The bibliometric analysis carried out indicates that Competitive Intelligence is closely linked to innovation processes in companies, facilitating its development. Furthermore, it highlights the importance that business management, together with the promotion of absorptive capacity and alignment around Competitive Intelligence will allow companies to improve their competitive advantages, as well as greater success with new products. Little research was found on aspects related to small and medium-sized enterprises and patents in relation to Competitive Intelligence. This research aims to show which are the most researched topics in relation to Competitive Intelligence, so that it can serve as support for future research, as well as for company managers in making decisions in relation to this topic.
\end{abstract}

Keywords: competitive intelligence; innovation; SciMAT; business intelligence

\section{Introduction}

Globalisation presents new challenges that considerably increase the complexity of the environment surrounding companies (Hitt et al. 2000). More specifically, the global economy has had a direct impact on competitiveness and security, which has changed these concepts and their approaches. Today's business environment is much more complex, where the interests of external operators generate a dynamic environment (Chaki 2015). This dynamism of today's business environment makes companies increasingly dependent on a system of early detection of changes in order to be able to respond appropriately (Kahaner 1996). However, companies need time and resources to adapt to the changing environment, where they will have to deal with risks and threats that undermine their security and sustainability. Therefore, companies need to develop complementary, synergistic, interactive and goal-oriented efforts in pursuit of shared objectives and interests (Gonzalvo 2015; Tuan 2016).

Against this background, Competitive Intelligence (CI) is presented as a strategic discipline that helps organisations to adapt to changes in the environment (Sewdass 2012) and to cope with industry disruptions (Vriens and Søilen 2014). CI allows an organisation a better understanding of the business and industry environment, as well as continuous learning from competitors' corporate and business strategies. In addition, it decreases 
the risk inherent in the choice of competitive strategies for an organisation, which is fundamental to achieving success in today's competitive conditions.

Competitive intelligence is not a recent business activity (Calof and Wright 2008). Although it has generally been associated with strategic and knowledge management (Shujahat et al. 2017), today it is recognised as a relatively new field of study (De Pelsmacker et al. 2005). Little is known about the scope of IC research and about IC as a field of academic study (Du Toit 2015). Furthermore, there is a diversity of approaches used caused mainly by the multidisciplinarity of the subject matter (Cavallo et al. 2020; Walker 1994). The first IC dynamics related to the business world were carried out in the knowledge areas of Business Administration and Management, Marketing and Information Sciences, and later evolved to Computer Engineering and Operations Research (Schwarz 2007; López-Robles et al. 2019a; Fleisher 2008). As with other fields of study where the domain and scope of application is varied, there is no consensus on the definition of Competitive Intelligence (Pellissier and Nenzhelele 2013).

It can be risky to undertake a bibliometric analysis of $\mathrm{CI}$ because of the different denominations that can be found. Bergeron and Hiller, published "Competitive Intelligence" in 2002 (Bergeron and Hiller 2002) where they analysed in detail the evolution of CI since its beginning, and warned that there is no globally accepted terminology. Terms such as Market Intelligence, Technology Intelligence and Organizational Intelligence (Kochen 1989) and Corporate Intelligence, Business Intelligence, Competitor Intelligence and Strategic Intelligence (Walker 1994) coexist. This heterogeneity of terms and definitions has been analyzed by numerous researchers (Du Toit 2015; Pellissier and Nenzhelele 2013; Bergeron and Hiller 2002; Colakoglu 2011). López-Robles et al. (2019a), identifies up to 10 definitions of intelligence included in the scientific literature. In a broad manner, we can define Competitive Intelligence as that activity that comprises the act of planning, selecting and obtaining information from various sources, in order to subsequently analyse, contrast, integrate and present it in a useful way to the level that has to make a decision (Sánchez 2015). Therefore, it is not only a matter of knowing what is going on (something that can be achieved without too much effort in the information age in which we find ourselves) but also of understanding what it means and acting accordingly (Sánchez 2015). A company has intelligence when it uses the information at its disposal to understand its real situation and that of its environment in the current context of high uncertainty and globalisation, and uses it in the decision-making process to manage risk, anticipate threats and detect (or create) opportunities, thus gaining an advantage over its competitors.

The multiple approaches, definitions and disciplines related to Intelligence can result in difficulties when investigating, just like the one that is presented. However, in relation to the business and organizational environment, the term Competitive Intelligence is positioned as one of the most developed and disseminated throughout the literature (López-Robles et al. 2019a), and we also consider that the term Competitive Intelligence is the one that presents a more global character and that gathers most of the aspects that organizational intelligence can show. However, we are aware of the possible consequences of focusing our literature review on the term Competitive Intelligence, as will be shown below.

The present research analyses the articles on Competitive Intelligence included in the Web of Science (WoS) database (Web of Science 2021). The main objective of this research is to detect the topics that have been most related to Competitive Intelligence, in order to identify the main approaches developed in published research. To this end, a bibliometric review of the publications that have dealt with this subject is carried out, in which, in addition to a descriptive statistical analysis of the published research, the most important authors and the most representative journals, the areas of research where most emphasis has been placed, as well as those that have not been sufficiently developed, will be recorded using bibliometric techniques. The article presented here provides an overview of Competitive Intelligence through the Web of Science database, which will help researchers to detect points of support for future research. It will also help business 
managers and administrators to compose an updated picture of the meaning of this concept and the implications it can have on the development of their business strategies.

\section{Theoretical Development}

Competitive Intelligence has its origins in Military Intelligence (Tej Adidam et al. 2012) and according to several authors its birth date backs to more than 5000 years ago in ancient China (Tao and Prescott 2000; Powell and Bradford 2000). In the literature on CI, there are frequent references to the manuscript of Sun Tzu, who wrote about 2400 years ago The Art of War (Sun 1988), which describes in detail how to develop intelligence for military applications. Closer to our own time, research on CI has been oriented according to the disciplinary approach from which the concept was analysed. The scientific literature on CI has evolved in parallel with the development of this subject. Until the 1980s, documents on CI were based almost exclusively on the collection of information for decision making (Du Toit 2015). Later, CI began to be positioned as a formal function within companies in the USA (Begg and Toit 2007), but it was not until the 1990s that CI began to gain momentum (Du Toit and Muller 2005). Gradually, it has been observed that the collection and correct use of good information has a direct impact on business results (Tej Adidam et al. 2012; Fleisher and Blenkhorn 2003), which has given rise to numerous studies on this aspect: the influence of the internet on the quality of information and organisational impact (Teo and Choo 2001); the ability of vendors and customers to adapt to CI, and its influence on the results obtained (Hughes et al. 2013); or the repercussions of CI mechanisms in large companies (Bernhardt 1994). However, criticisms of the effect of CI on organisations also appear in the literature (Kahaner 1996), pointing to the difficulty of measuring the benefits of CI or the lack of interest in the scientific literature.

The relevance of CI in companies is clear. In order not to make mistakes which can be detected in research on CI that directly focus on a specific aspect, in this theoretical framework, we believe it is better to position this discipline before proceeding to describe the materials, methods, and results obtained in this research.

\subsection{Intelligence and Competitive Intelligence}

Broadly speaking, intelligence is information properly processed into knowledge to support the timely decision-making of a particular user in a given set of circumstances. It is an intangible asset of great value in many areas and is based on knowledge. Intelligence is therefore the application of knowledge to integrate, interpret, analyse, and evaluate information relevant to a given event that poses a threat or an opportunity for a company or a country. Intelligence thus becomes the product. It is about assessing a target in order to align decisions and actions to take advantage of opportunities and counter threats. However, it not only provides knowledge about the environment, it also guides companies to interact with it.

Many adjectives can be found for the term intelligence. Its multidimensional nature leads to different typologies, some of which have already been discussed: market intelligence, competitor intelligence, technological intelligence (Vroman 1995), strategic and social intelligence (Rouach and Santi 2001), or structural-organisational intelligence (Zangoueinezhad and Moshabaki 2009). The vast majority of existing research has been carried out in developed markets in the US and Europe (West 1999; Gračanin et al. 2015; Bartes 2014) and in emerging markets such as India (Tej Adidam et al. 2012) and China (Bao et al. 1998; Tao and Prescott 2000). This research is and has been beneficial to the development of the CI literature (Tahmasebifard 2018) but is insufficient to assess the influence of CI on firm performance.

A company has intelligence when it uses the information at its disposal to understand its real situation and that of its environment in the current context of high uncertainty and globalization. Then it is used in the decision-making process to manage risk, anticipate threats, and detect (or create) opportunities, thus achieving a position of advantage over its competitors. The possible sources of information that a company can use for Competitive 
Intelligence are numerous and could be grouped into documented and undocumented sources (Arroyo Varela 2015). Documented sources are more accessible and easier to obtain and do not require a company's exposure, for example: Patent Registers, Statistics, Market Studies, Professional Journals, Books, Databases, or Catalogs. On the other hand, non-documented sources require planning and choice of information sources: Customers, Suppliers, Advisors, Collaborators, Competitors, Chambers of Commerce, Governments, etc. New emerging technologies (e.g., big data, internet of things and artificial intelligence) are presented as tools for greater openness, convergence, and knowledge creation, which will contribute to a dynamic and sustainable environment (Park 2017).

$\mathrm{CI}$ includes obtaining, analysing, interpreting, and evaluating information relevant to a company about its customers, its competitors, the structure, and dynamics of its industry (Fleisher and Bensoussan 2007; Vriens and Søilen 2014), the competitive forces at work in the market, technological, and organisational innovations, the economic, technological, and legal context (González Cussac 2013) and monitoring the changes that occur in these frameworks.

The aim is for a company to be able to proactively identify trends and transformations in the environment, detect and prevent threats, identify, and seize opportunities. In this sense, $\mathrm{CI}$ is linked to intelligence of a strategic nature and to Knowledge Management (McGonagle and Vella 1998; Erickson and Rothberg 2013; Montgomery and Weinberg 1979). From this point of view, intelligence can help in areas where managers want a sustainable competitive advantage. Hence, we choose to place intelligence at a strategic level, and thus become part of organisational thinking. CI does not replace the areas of market research, strategic planning, marketing, financial analysis, and security, but reinforces and supports the requirements of continuous decision making in these functions and the needs of their key managers. Thus, intelligence is already a perfectly legal and growing ingredient in the formulation of corporate strategy (Rouibah and Ould-Ali 2002).

Therefore, thanks to $\mathrm{CI}$, the company adapts to the environment to improve its position vis-à-vis its competitors and achieve success. Intelligence enables the preparation of a company's strategies and tactics, the development of innovation policies to take advantage of opportunities, the implementation of appropriate measures to prevent or reduce risks (Fernández 2016) and impacts of threats, as well as decision-making and the implementation of appropriate actions to achieve competitive advantage (Qiu 2008).

Analysis of information is a key aspect. Analysis is not only the reorganisation of data and information into a new format, but also the process of applying reasoning and analytical techniques to convert and interpret the key lines into a product that enables decision making.

According to Viviers et al. (2005), the Competitive Intelligence process can be summarised by the following cycle:

- Plan the collection of information according to key intelligence needs.

- Gathering information from various sources.

- Use analysis tools to analyse information.

- Packaging information and communicating it to management

Although Porter (1980) already indicated that most companies performed these tasks in an informal way, in his opinion, it was necessary to implement a continuous and systematic structure in organisations to detect and analyse business opportunities and threats in the environment. Research on CI has grown significantly in the last decades, where it is positioned as an independent thematic field (Tej Adidam et al. 2009; Köhn 2012). However, this may not be sufficient-the people who interpret the analysis should either have direct contact with the decision-makers or be part of the decision-making team. This is difficult to achieve within the company's management. Although top management plays an important role in the implementation of IC dynamics, the absorptive capacity of operational managers is a key part of the development of IC (Elbashir et al. 2011). 


\subsection{Bibliometric Analysis on Competitive Intelligence}

Numerous bibliometric analyses have been carried out in relation to Competitive Intelligence. The proliferation of these literature reviews has been based on the relatively novel discipline outside the military and especially on the different interpretations, definitions, and development that Competitive Intelligence presents.

López-Robles et al. (2020a) publish the article "Understanding the intellectual structure and evolution of Competitive Intelligence: a bibliometric analysis from 1984 to 2017", where about 6000 publications related to CI from the Scopus database divided into five periods are analysed. In the bibliometric analysis carried out, they highlight which are the key topics that have contributed most to the field of IC from different disciplines. The authors distinguish two main ways in which IC has been divided: on the one hand, the topics related to knowledge management, decision process, foresight, collaboration, and management, and on the other hand a more recent current related to data management, data mining, storage, information management, etc. This same author also publishes, together with other researchers in 2018 (López-Robles et al. 2019b), the article "Mapping the structure and evolution of JISIB: A bibliometric analysis of articles published in the Journal of Intelligence Studies in Business between 2011 and 2017", the researchers analyse the 92 articles published in that Journal in recent years, as JISIB is considered one of the few academic journals specialized in IC and its equivalent terms. Its main contribution is the consolidation of IC as an emerging field of study that is analysed from very different approaches. In this same line we also find the article by Teixeira and Cristina (2017), publish in 2017 "Evolution of the competitive intelligence based on metric study of its literature", this manuscript performs a bibliometric analysis of 3453 articles from the Scopus database between 1984 and 2013, highlighting that the first research on CI, were oriented to the study of this concept and the justification of this working model. Subsequently, and logically, research has been concerned with the development and evolution of IC.

Bibliometric studies oriented to CI coincide with the interdisciplinary nature of the concept, which is approached from very different areas of knowledge. On this aspect, the bibliometric analysis conducted by Correia et al. (2019) called "Characteristics of the scientific production on the subject of competitive intelligence: a bibliometric analysis", and carried out on the Scopus database, highlights how CI is presented as a point of support for other areas of knowledge, distinguishing up to seven related areas. The author also indicates the need for systematic reviews of research content to better understand the lines of knowledge that are being developed. do Prado and Celso de (2018) publish a systematic review of IC publications entitled "Analysis bibliometric 1990-2014: competitive intelligence", whose main interest is the search for IC models published in the last 25 years in international journals. In this review they identify a total of 22 models to define CI processes in the company, concluding that the variety of models found is mostly motivated by the different names used for the same phases of the process, indicating the advantage of using a standard for the development and evaluation of CI processes in organizations.

There are other literature reviews on IC that have a high impact and develop other interesting approaches. Bergeron and Hiller (2002), published a manuscript in 2005 in which they analysed in detail the factors related to IC in publications between 1994 and 2000. This document shows how IC is spreading in all types of organizations. It is also noteworthy how the authors point out the different orientations of IC depending on the country or geographical area where it is analysed. Finally, they indicate that there is a need for a greater presence in the scientific literature of articles that address the understanding and development of products and services related to IC. Other researchers have published reviews on CI or associated factors from different perspectives: Shujahat et al. (2017) "Strategic management model with lens of knowledge management and competitive intelligence A review approach"; Xu et al. (2011) "Mining comparative opinions from customer reviews for Competitive Intelligence"; LópezRobles et al. (2020b) "The relationship between Business Intelligence and Competitive Intelligence: a retrospective analysis and literature review from 1959 to 2017" and López- 
López-Robles et al. (2019a) "30 years of intelligence models in management and business: A bibliometric review".

The present research complements other bibliometric studies conducted on CI by analysing the scientific literature published in the Web of Science database. Using bibliometric techniques and grouping all the articles in the sample in a single period of time (from 1985 to 2021), the aim was to identify the topics related to the study of IC with the greatest centrality and density. In this way, and over the years, we have detected which topic has been the most visible and what relationship it has had with the different approaches used by the researchers, as well as highlighting those topics with a scarce scientific production. The main contribution of this article, which distinguishes it from other studies, is the general approach of the search carried out without focusing on any particular aspect or specific journal, in addition to the model of analysis proposed. The results obtained, which are detailed in the following sections, demonstrate the suitability of the study carried out.

\section{Materials and Methods}

In order to respond to the objective of this research, the authors have examined the articles published in the Web of Science (WoS) database related to Competitive Intelligence. The bibliometric techniques used, analysed the published articles objectively (AlbortMorant and Soriano 2016). The bibliographic sample selected in this research, which is detailed below, brings together the articles in the WoS database that deal with Competitive Intelligence. The metric analysis used has made it possible to determine the relationship between the manuscripts in the sample, as well as the main adjacent topics addressed in these documents. Firstly, a descriptive statistical analysis is carried out to highlight the main indicators of activity in the literature on this subject. Secondly, a selection is made of those articles that lead the most used approaches in the analysis of Competitive Intelligence and that mark the tendencies of this field of research, in this way an exposition of the most present topics is made and those that have less presence in the research related to Competitive Intelligence are detected.

\subsection{Materials}

The analysed sample of documents is extracted from the Web of Science (WoS) database (Web of Science 2021). This database makes available to researchers and other interested parties, a collection of more than 68 million documents from 1900 to the present day. Most of the journals included are indexed in Journal Citation Reports, which ensures the high quality of the documents available. The search was carried out on 15 April 2021, with the search criteria being the expression: "Competitive Intelligence". In the first step, those articles were selected where the expression "Competitive Intelligence" was included in the Title of the Article, Keywords, Keywords Plus or Abstract. The authors are aware that limiting the search to the term "Competitive Intelligence" may bias the sample of articles obtained, due to the other names used to describe these business dynamics. However, we consider that the term Competitive Intelligence is the most generic and therefore the most appropriate of all those used. In addition, it has been possible to verify that the search configuration established has provided a valid sample. Due to the multidisciplinary approach of this subject, no area of knowledge has been restricted in the search performed. The search was restricted to the Science Citation Index Expanded (SCI-EXPANDED), Social Sciences Citation Index (SSCI) and Emerging Sources Citation Index (ESCI). Due to the multidisciplinary approach of this subject, no area of knowledge has been restricted in the search carried out. Finally, no document was discriminated according to the year of publication, and no minimum number of citations received was required, so that all documents were considered, even if they had not yet reached their maximum impact. This search configuration yielded a total of 637 documents. This first sample was thoroughly reviewed by the authors and after reading the abstract a total of 48 documents were discarded, so the final sample for our analysis is 589 documents. 


\subsection{Software}

The software chosen for the bibliometric analysis was SciMAT. This software application allows the construction of strategic maps and thematic networks with respect to a set of documents. The unit of analysis used was the keywords of the author and the keywords which corresponded to the source of publication. In our analysis of the literature on Competitive Intelligence, the strategy maps will allow us to detect which topics are the most addressed by researchers in relation to $\mathrm{CI}$, and among them, we will highlight which are considered to be driving, basic, peripheral, emerging or declining research topics. On the other hand, the thematic networks will represent the internal network of the themes of each cluster created; this thematic network is based on co-occurrences.

\section{Results}

\subsection{Indicators of Activity in the Competitive Intelligence Literature}

The sample of literature related to Competitive Intelligence in the WoS database has reported a total of 589 papers between 1985 and 2021 in the category Business Economics. The first article of the selection made is the one published in 1985 by Zinkhan and Gelb (1985) called "Competitive Intelligence Practices of Industrial Marketers" in the journal Industrial Marketing Management. As can be seen in Figure 1, the number of publications has not been homogeneous over the years; moreover, until the first decade of the 21st century, the number of published articles does not reach ten papers per year. It is expected that in 2021 there will continue to be an upward trend in the number of documents on Competitive Intelligence, in Figure 1 only those published in the first quarter of this year are shown. If the number of documents in 2021 follows the same pace as shown in the first quarter, we can expect to reach 50 articles for CI in 2021.

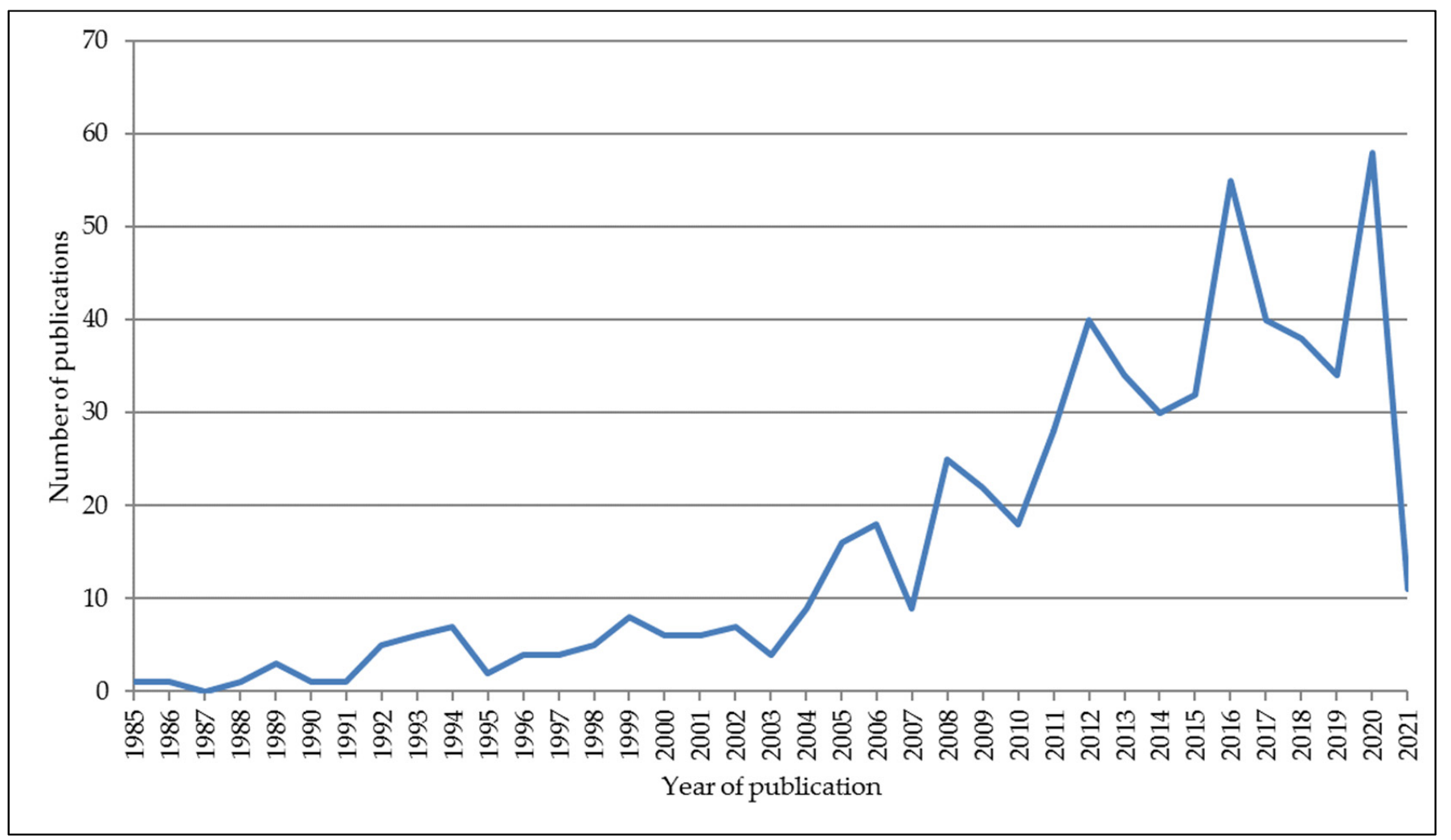

Figure 1. Publications over time on Competitive Intelligence $(n=589)$. Source: Prepared by the authors on the basis of WoS data. 
The articles in the sample of this research most cited by the scientific community date from the end of the 20th century, where we can highlight: "Moral awareness in business organisations: Influences of issue-related and social context factors" with 252 citations (2000), by Butterfield et al. (2000); "A confessional account of an ethnography about knowledge work" with 211 citations (2000) by Ulrike Schultze (2000); "Innovation forecasting" with 161 citations (1997) by Watts and Porter (1997); and "Knowledge management technology and the reproduction of knowledge work practices" with 150 citations by Schultze and Boland (2000). Another article with a high number of citations, published by Rohrbeck and Gemünden (2011) entitled "Corporate foresight: Its three roles in enhancing the innovation capacity of a firm" which has 146 citations, where strategy is linked to innovation processes, aspects that have had a remarkable continuity as we will see below.

The 589 papers analysed were published by a total of 1143 authors. The most prolific authors are Calof, J. with 14 manuscripts and 190 citations received, and du Toit, ASA. also with 10 papers and 209 citations received. As Du Toit points out, competitive intelligence practitioners do not write much about what they do, competitive intelligence research is mostly written by academics teaching CI in higher education institutions (Fleisher 2001), an aspect that is confirmed in this sample. More than $98 \%$ of the authors in this sample have written 4 or less articles. Table 1 shows the authors who have published 5 or more articles, as well as the dates of their first and last CI paper in the sample analysed and the number of citations received from other publications included in WoS.

Table 1. Authors who have published five or more articles on Competitive Intelligence.

\begin{tabular}{cccc}
\hline Author & Number of Articles & $\begin{array}{c}\text { Year of Publication } \\
\text { First and Last Article }\end{array}$ & Cited by \\
\hline Calof, J & 14 & $2008-2020$ & 190 \\
du Toit, ASA & 13 & $2003-2019$ & 209 \\
Muller, Marie Luce & 10 & $2005-2008$ & 109 \\
Rothberg, Helen N. & 8 & $2009-2017$ & 80 \\
Erickson, G. Scott & 8 & $2009-2017$ & 80 \\
Sewdass, Nisha & 7 & $2012-2020$ & 55 \\
Soilen, Klaus Solberg & 7 & $2012-2017$ & 46 \\
Tuan, Luu Trong & 7 & $2013-2017$ & 88 \\
Wright, Sheila & 7 & $2008-2013$ & 118 \\
Agnihotri, Raj & 6 & $2011-2020$ & 125 \\
Bisson, Christophe & 6 & $2012-2020$ & 35 \\
Munoz-Canavate, Antonio & 6 & $2009-2019$ & 4 \\
Koseoglu, Mehmet Ali & 5 & $2016-2020$ & 17 \\
Yap, Ching Seng & 5 & $2011-2018$ & 87 \\
Fleisher, Craig S. & 5 & $2008-2010$ & 51 \\
Okumus, Fevzi & 5 & $2016-2020$ & 112 \\
Viviers, Wilma & 5 & $2005-2020$ & 11 \\
Guimaraes, Tor & 5 & $2009-2019$ & \\
\hline
\end{tabular}

Source: Prepared by the authors on the basis of WoS data.

The 589 articles have been published in a total of 304 journals. In the analysis of these, the "Journal of Intelligence Studies in Business" stands out strongly, with 73 papers in the sample (12.4\%). The remaining Journals have published less than 18 manuscripts in this analysis, which gives an idea of the dispersion of the publications in this subject and their interdisciplinary nature. Table 2 shows the journals with the highest number of publications, the dates of their first and last publication in this sample and the 2019 Journal Citation Report or Scopus quartile. 
Table 2. Journals that have published on Competitive Intelligence. Quartile 2019 and Total Items.

\begin{tabular}{|c|c|c|c|c|c|c|c|c|c|}
\hline N. & Journal & Q1 & Q2 & Q3 & Q4 & Total Items & $\%$ & First Doc. & Last Doc. \\
\hline 1 & Journal of Intelligence Studies in Business & - & - & $X^{*}$ & - & 73 & $12.4 \%$ & 2011 & 2020 \\
\hline 2 & $\begin{array}{c}\text { South African Journal of Information } \\
\text { Management }\end{array}$ & - & - & - & - & 17 & $2.9 \%$ & 2005 & 2016 \\
\hline 3 & $\begin{array}{c}\text { International Journal of Information } \\
\text { Management }\end{array}$ & $\mathrm{X}$ & - & - & - & 11 & $1.9 \%$ & 1994 & 2021 \\
\hline 4 & Perspectivas em Ciencia da Informaçao & - & - & - & - & 11 & $1.9 \%$ & 2012 & 2020 \\
\hline 5 & Profesional de la Información & - & $X^{*}$ & - & - & 10 & $1.7 \%$ & 2006 & 2016 \\
\hline 6 & World Patent Information & - & $X^{*}$ & - & - & 9 & $1.5 \%$ & 2005 & 2017 \\
\hline 7 & Foresight and STI Governance & - & $X^{*}$ & - & - & 8 & $1.4 \%$ & 2015 & 2020 \\
\hline 8 & Journal of Strategic Marketing & - & $X^{*}$ & - & - & 8 & $1.4 \%$ & 2008 & 2020 \\
\hline 9 & Marketing Intelligence \& Planning & - & $X$ & - & - & 8 & $1.4 \%$ & 2005 & 2014 \\
\hline 10 & Industrial Marketing Management & $X$ & - & - & - & 7 & $1.2 \%$ & 1985 & 2020 \\
\hline 11 & Long Range Planning & $x$ & - & - & - & 7 & $1.2 \%$ & 1989 & 1998 \\
\hline 12 & Scientometrics & - & $x$ & - & - & 7 & $1.2 \%$ & 2006 & 2018 \\
\hline
\end{tabular}

Source: Prepared by the authors on the basis of WoS data. Q1, Q2, Q3 and Q4 correspond to the quartile of Journal Citation Report or Scopus (2019). $X^{*}$ corresponds to quartile in Scopus database.

Of the sample analysed, only two journals, the Journal of Intelligence Studies in Business and Marketing Intelligence $\mathcal{E}$ Planning, can be considered to focus on the publication of articles on intelligence. Marketing is very present in the topics addressed by the journals. Most of the top 12 journals based on the number of articles published in this sample belong to the first $(\mathrm{Q} 1)$ or second $(\mathrm{Q} 2)$ quartile of Journal Citation Report or Scopus database (2019).

In summary, research on Competitive Intelligence is presented from very different areas of knowledge and no single author stands out from the rest. It is from the first years of the 20th century onwards when research on this subject offers a greater number of publications.

\subsection{Analysis of Competitive Intelligence Research}

In order to carry out a detailed analysis of the field of research on Competitive Intelligence, and after the descriptive analysis carried out, we conducted a bibliometric study that will allow us to detect those topics that lead this field. For the analysis, the 589 documents of the selected sample from 1985 to 2021 are included. The strategic map shown in Figure 2 represents those clusters with a greater presence in the sample by means of spheres. Depending on the relationship between centrality and density, each cluster occupies a position on the strategy map. The results represented in the strategy map place the Innovation cluster with 123 documents, centrality rank of 1, and density rank of 1 as the most important driving theme (Table 3). It is the most developed theme in this sample and therefore projects the trends in Competitive Intelligence research. Also appearing as driving themes, although with a much lower degree of intensity, are the Orientation, Strategy, and Customer Information clusters with 37, 24, and 11 documents respectively. As basic themes, we find the clusters Organisational Intelligence and Information with 16 and 34 documents respectively, these themes have a strong centrality, but low density, symbolising those themes that are considered central and generic (lower right quadrant of Figure 2). Continuing with the analysis of the strategy map in Figure 2, Business-Intelligence with 33 documents and Exploration with five documents are considered peripheral themes, which are those that correspond to very specialised themes due to their high density, but weak centrality. Finally, we find the clusters Text Mining, Supply Chain and SME (Small and medium enterprises), with 11,8 , and 4 documents, respectively, in the lower left quadrant of Figure 2, these topics are considered emerging or declining, i.e., they may be gradually gaining importance, or on the contrary they are losing presence in the research. This will depend on their evolution in the following years being analysed. 


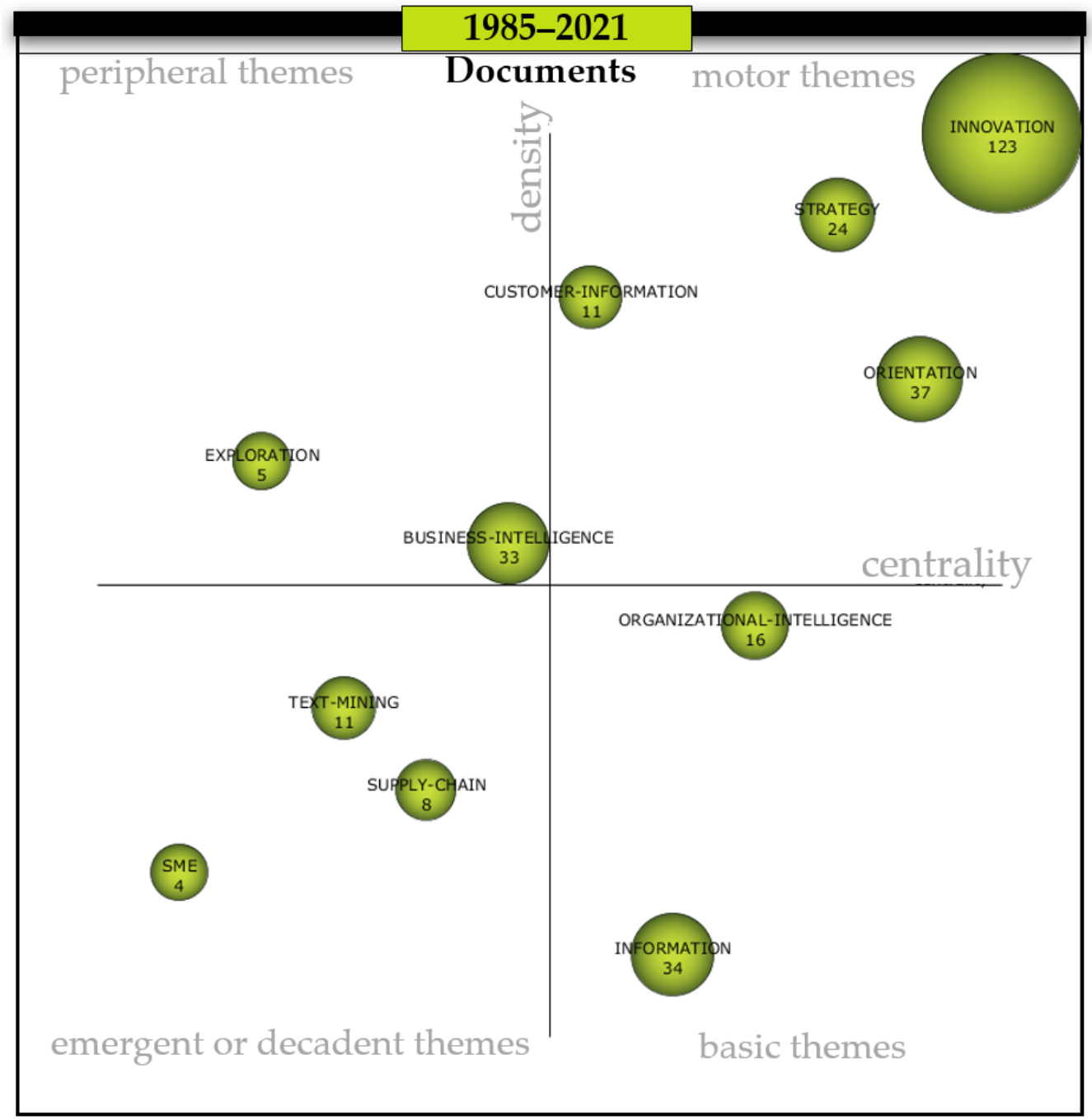

Figure 2. Strategic Map. Primary Documents period 1985-2021. Source: Prepared by the authors on the basis of SciMAT data.

Table 3. Cluster period 1985-2021.

\begin{tabular}{|c|c|c|c|c|c|c|c|}
\hline Name & Centrality & $\begin{array}{c}\text { Centrality } \\
\text { Range }\end{array}$ & Density & $\begin{array}{c}\text { Density } \\
\text { Range }\end{array}$ & Documents & Citations & H-Index \\
\hline Innovation & 101.93 & 1.00 & 47.32 & 1.00 & 123 & 1846 & 19 \\
\hline Orientation & 48.61 & 0.91 & 13.86 & 0.73 & 37 & 531 & 11 \\
\hline Strategy & 33.31 & 0.82 & 21.44 & 0.91 & 24 & 243 & 11 \\
\hline $\begin{array}{l}\text { Organizational } \\
\text { Intelligence }\end{array}$ & 22.51 & 0.73 & 9.87 & 0.45 & 16 & 144 & 5 \\
\hline Information & 20.51 & 0.64 & 3.64 & 0.09 & 34 & 530 & 11 \\
\hline $\begin{array}{l}\text { Customer } \\
\text { Information }\end{array}$ & 18.69 & 0.55 & 18.8 & 0.82 & 11 & 245 & 5 \\
\hline Business Intelligence & 18.25 & 0.45 & 11.97 & 0.55 & 33 & 497 & 9 \\
\hline Suply Chain & 13.88 & 0.36 & 7.94 & 0.27 & 8 & 185 & 4 \\
\hline Text Mining & 5.37 & 0.27 & 7.99 & 0.36 & 11 & 560 & 6 \\
\hline Exploration & 3.38 & 0.18 & 13.12 & 0.64 & 5 & 156 & 3 \\
\hline SME & 3.26 & 0.09 & 6.48 & 0.18 & 4 & 35 & 4 \\
\hline
\end{tabular}


Bearing in mind that the most significant cluster is Innovation, the 123 documents that comprise it were analysed in detail in order to detect the main research trends with respect to Competitive Intelligence. If we analyse the thematic network of the Innovation cluster (Figure 3), we find themes such as Competitive-Intelligence, Entrepeneurship, HotelIndustry, Management, New-Products, Performance, Strategic-Leadership, Absortive-Capacity, Industry-Clockspeed, System-Success, and Dynamic-Capability.

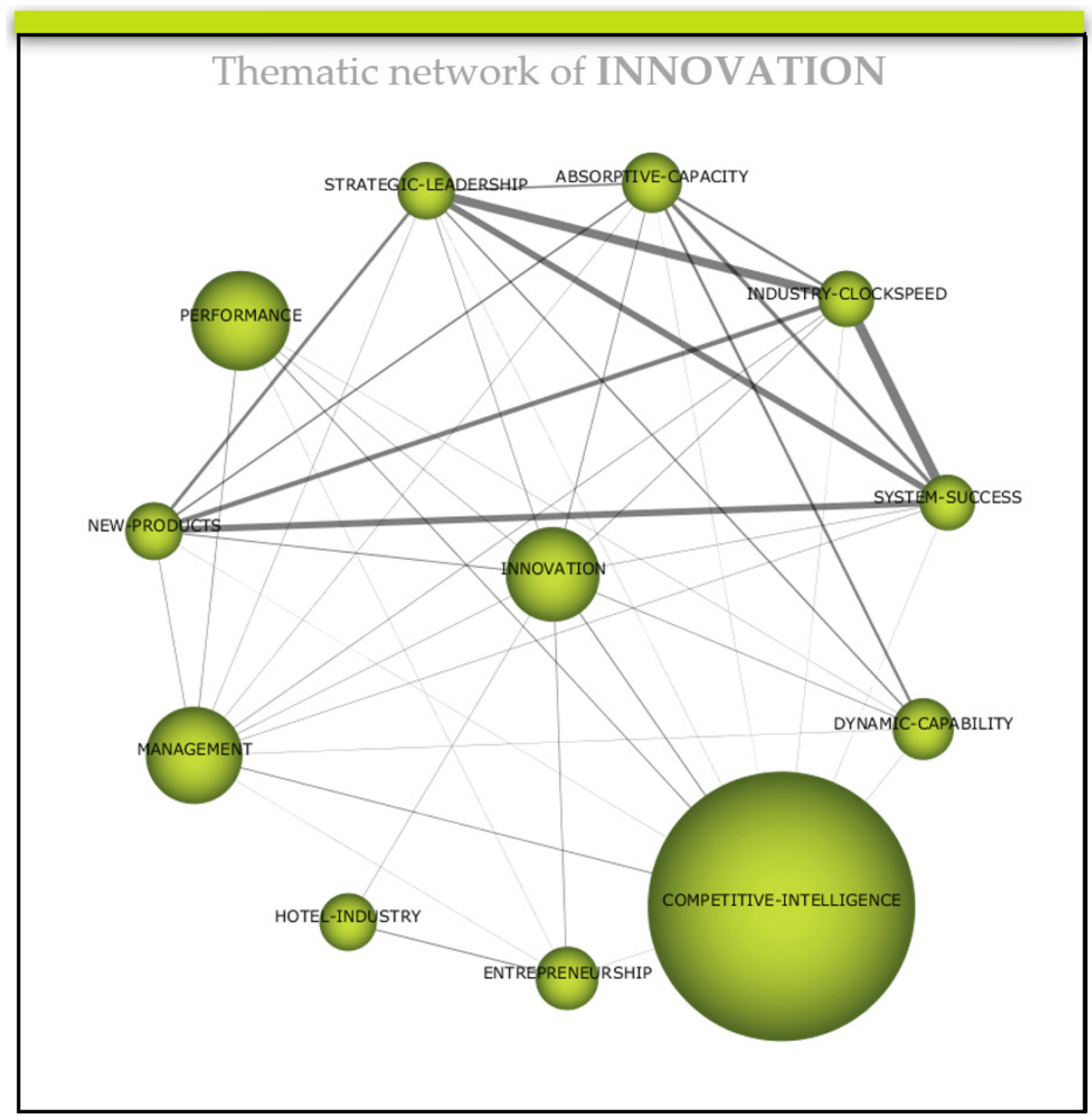

Figure 3. Thematic network of INNOVATION. Primary Documents period 1985-2021. Source: Prepared by the authors on the basis of SciMAT data.

The Innovation cluster presents the most important driving theme in the sample with respect to Competitive Intelligence. One third of the 114 papers in the Innovation cluster address the impact that the use of CI has on firms, and this impact is mainly measured in terms of gaining competitive advantage, either in the form of new products (Homburg et al. 2017), knowledge sharing (Tuan 2016), changes in firm strategy (Maguire 2010; Ghannay and Mamlouk 2012), or directly measuring organisational performance (Tahmasebifard 2018). The association between $C I$ and innovation has been addressed in multiple research 
(Calof and Sewdass 2020), where it is considered that the CI information used by firms has a direct effect on their innovation performance, and that this mainly comes from specialised suppliers and other organisations (Tanev and Bailetti 2008; Caseiro and Coelho 2019; Kuester and Rauch 2016; Asghari et al. 2020).

Another of the most visible themes in the documents that link innovation with $\mathrm{CI}$ is the analysis of the company's own management with respect to CI. Numerous references have been found that recognise the importance of the organisation and management of companies in relation to $\mathrm{CI}$, although few documents have addressed the subject from the perspective of small and medium-sized companies (Tarek et al. 2016; Tarek et al. 2019). The company's promotion of projects related to strategic exploration is one of the most important factors that lead to the failure or abandonment of these plans (Tahmasebifard 2018). The figure of managers and the management of the organisation itself are positioned as key in the performance of CI (Lesca and Caron-Fasan 2008). Managers must model and inspire the members of their organisation (Trong Tuan 2013), as well as promote an innovative culture in the implementation of strategic plans (Ramaseshan et al. 2013). The absorptive and adaptive capacity (Guimaraes et al. 2018), the demonstrated dynamic capabilities (Heinrichs and Lim 2008) or resources employed by organisations, as well as the alignment of the company's staff will have a significant impact on the successful implementation of CI.

Researchers have also published on the procedures for the generation and use of CI in companies. Many studies focus on marketing and sales strategies (Hughes et al. 2013; Homburg et al. 2017; Ramaseshan et al. 2013) as a field of application of CI, where it is also used as a learning model within the department (Dishman and Pearson 2003). CI is considered a useful tool for marketing managers and will increase their strategic responsiveness (Heinrichs and Lim 2008). The rise of Information Communication Technologies (ICTs) has also been associated with Competitive Intelligence and innovation processes (Gordon et al. 2008), where some authors highlight how the use of social networks, the spectacular development of the Web, big data and other tools have generated an exponential growth in the information available (Lichtenthaler 2005; Rothberg and Erickson 2017). Finally, it is worth highlighting those publications that address theoretical perspectives (Chevallier et al. 2016; Hoppe 2013; Hughes 2017) and reviews on this subject (López-Robles et al. 2019a; Talaoui and Kohtamäki 2020).

The documents analysed that relate Competitive Intelligence to Innovation can be grouped into three main families. On the one hand, those that analyse the impact that $\mathrm{CI}$ has on the innovation processes of companies, which mainly deal with case studies and calculate the success obtained in new products or in the company's own organisational system. A second group would be those documents that study, from a theoretical framework, CI applied to the company and its departments, as well as an analysis of the tools for knowledge management. Finally, a third group of research papers would be those that analyse the company and focus on the dynamic and absorption capacities that organisations must have in order to make use of $\mathrm{CI}$, as well as the role of managers and the importance of the culture of intelligence in the organisation.

\section{Discussion}

Competitive Intelligence has been a field of research developed mainly from a military point of view, going back several centuries. In the last decades of the 20th century, scientific literature began to develop that applied these techniques related to National Security to the concept of business. Today's business environment presents new challenges where globalisation and the interests of external operators have shaped a changing and dynamic environment. The first publication on Competitive Intelligence in our sample dates from 1985, "Competitive intelligence practices of industrial marketers" published by Zinkhan and Gelb (1985) in the journal Industrial marketing management. Interestingly, the title of this first journal seems to be a premonition of the large amount of research that would later deal with marketing and CI. In fact, in academic and professional circles it is common to find 
publications that address definitions, similarities and differences between marketing and competitive intelligence, as well as the term business intelligence (Erickson and Rothberg 2013; Wright and Calof 2006; Fleisher 2008). On this aspect, Du Toit, ASA in his 2015 publication entitled "Competitive intelligence research: an investigation of trends in the literature", indicates that the most used term in the scientific literature is "Competitive Intelligence", followed by "Business intelligence" and "Marketing intelligence". However, we must understand that they do not mean the same thing, although several authors in different epochs and latitudes have used indistinctly one term or the other to refer to intelligence in companies, we could comment that the term Marketing Intelligence is oriented to obtain the widest possible image of the market, understanding the customers and their behaviour as consumers. On the other hand, the term Competitive Intelligence is linked to a study of the environment, where information about the company's competitors is also collected and analysed, which positions it as a more complete tool. In other words, Marketing Intelligence can be part of the company's Competitive Intelligence strategy, but not the other way around. This is why the term Competitive Intelligence has been used as the basis for this bibliometric study.

It was not until the early years of the 21st century that we found a literary production of a certain volume, which also happens to have the greatest impact on the scientific community in terms of the number of citations received. The most prolific authors are Calof, J. and du Toit, ASA, with 14 and 13 publications each, respectively, although the most cited by other researchers are Butterfield, KD. and Schultze, U. The journals that have published on CI have been very varied in terms of the subject area of the journal, although there is one publication that stands out above the rest, the Journal of Intelligence Studies in Business, which accounts for more than $12 \%$ of the documents analysed. The aforementioned diversity of concepts related to Competitive Intelligence is also evident in the names of the journals that contribute most articles to the sample: Journal of Intelligence Studies in Business; South African Journal of Information Management; and International Journal of Information Management.

This research has carried out a review of the literature on Competitive Intelligence, the main objective of which has been to detect the topics most addressed by researchers in relation to Competitive Intelligence. At the same time, it underlies those that have received less attention. Thus, supporting the scientific community for future research and providing a vision to facilitate decision-making in business organisations.

Of the 637 documents included in the initial search, 589 were selected to form the sample for the analysis. The sample was obtained from the Web of Science database without discarding any document according to its year of publication or citations received. From this sample, once the descriptive analyses had been carried out, 123 documents were selected that corresponded to the Innovation cluster, which due to its density and centrality was considered the most important driving theme, since the other driving themes detected, Strategy, Customer Information and Orientation, have a very low strength in relation to the Innovation cluster. The analysis of these 123 documents of the Innovation cluster provided an exhaustive view of those themes that relate Competitive Intelligence to Innovation.

Innovation is a necessity for all organizations in order to compete in a dynamic and globalized market. Innovation has positioned itself as the main topic in the IC research that has been analysed; it is the topic with the greatest centrality, which implies that it is interconnected with most of the adjacent IC topics (Figure 3). Innovation is positioned as a vehicle to achieve the IC dynamics that an organization wishes to obtain, whether in its processes, products, or services, and this is logical in a certain sense. We are in the information age, changes in markets occur and spread instantaneously and organizations have to learn to adapt to the environment quickly. The emergence of the Internet and other digital technologies has opened up a new set of information sources, not only for searching, but also for sharing (Veugelers et al. 2010).

This review has allowed us to group the documents into three thematic families: The first of these is oriented towards the analysis of case studies and evaluation of the 
success of CI strategy with respect to innovation processes; a second grouping would be those documents that study from a theoretical framework the CI itself applied to the company; and finally a third family would be composed of those manuscripts that analyse the company and focus on the unique characteristics and dynamic and absorptive capacities that organisations must present.

The documents analysed in this research have shown an appreciable dispersion of approaches in the treatment of CI, somewhat more moderate in its relationship with Innovation, where a certain consensus has been demonstrated in the research analysed. The impact of CI on innovation processes within the company is positive and it is presented as a key tool in business strategy (Arroyo Varela 2015). However, despite the multitude of topics addressed by researchers in relation to $\mathrm{CI}$, some fields that should have a greater presence are detected. One of these is research on CI in small and medium-sized enterprises. CI is still in its infancy in the business world, and companies often do not have the infrastructure or the necessary knowledge to implement an CI system. To address these constraints, innovation must be presented as a determining factor in order to help these types of companies to position themselves in the market (Juillet 2012). One of the subjects that is not often dealt with is patents. Patents are also one of the most important sources of information for competitive intelligence. The patent scene has evolved a lot in the last 40 years (Berkowitz 1993), and open innovation practices can be the key for all types of organisations to gain access to this intellectual capital (Leydesdorff and Ivanova 2016).

In relation to other bibliometric studies analysed, the findings of this manuscript coincide in the high diversity of concepts, disciplines, and approaches used to refer to competitive intelligence (Bergeron and Hiller 2002; López-Robles et al. 2019a; López-Robles et al. 2019b; Teixeira and Cristina 2017; Correia et al. 2019; do Prado and Celso de 2018). Also, although the analysed manuscripts come from different sources and time periods (JISIB, Scopus, WoS, ABI/Inform, RBS), the most notable authors and journals in this subject are similar. However, it is significant that in most of these bibliometric analyses of IC-related literature, the Innovation theme, which in our analysis is positioned as the most important driving theme, does not appear with much intensity. This may be due to the different approaches taken by the researchers, as well as to the quantitative nature of the article in some cases. López-Robles et al. (2019a), points out among other topics, the dynamics of Innovation as the main theme in the last years of the analysed period. It is necessary to reach a consensus in the definitions and use of the terms Competitive Intelligence, Marketing Intelligence, Business Intelligence, and others, because sometimes very similar definitions are found referring to different terms. In other words, there are multiple definitions and terms in the scientific literature to describe a process that is based on the same business dynamics.

Business leaders and managers must direct part of their resources towards planning, searching, analysing, and using relevant information from their environment in order to increase their competitive advantages. To this end, it will be essential to create a collaborative environment, both internally and externally. Open Innovation dynamics are a key tool in this process. Not only large corporations should promote CI techniques, small and medium-sized companies should position themselves as entities that are very interested in this strategy, which is presented as key to their sustainability (Leydesdorff and Ivanova 2016).

\section{Conclusions}

The results obtained indicate that both research interest in CI in companies and its implementation in them is continuously increasing. The descriptive statistical analysis reveals that the scientific production is very distributed, both in relation to the number of authors and the journals that have published on CI, with few specialists being found. Although the adjacent topics that appear in research on CI are multiple, a bibliometric analysis shows the Innovation cluster as the one with the greatest centrality, which strongly links CI with innovation processes within the company. Finally, an insufficient number 
of publications related to $\mathrm{CI}$ in small and medium-sized enterprises has been detected, as well as with respect to patents.

The research carried out is not without limitations. The selection of documents was carried out only in the Web of Science (WoS) database, which may have led to the omission of articles of interest not included in this database. On the other hand, the different interpretations and definitions used for Competitive Intelligence may have led to a bias in the search carried out. Likewise, a more extensive analysis of the rest of the driving themes detected could provide some aspects not reflected in this research. Nevertheless, we consider that the sample of 589 articles is sufficient for the purpose sought.

Funding: This research received no external funding.

Acknowledgments: We are very grateful to University of Malaga.

Conflicts of Interest: The authors declare no conflict of interest.

\section{References}

Albort-Morant, Gema, and Domingo Ribeiro Soriano. 2016. A bibliometric analysis of international impact of business incubators. Journal of Business Research 69: 1775-79. [CrossRef]

Arroyo Varela, Silvia. 2015. Inteligencia Competitiva: Una Herramienta Clave en la Estrategia Empresarial. Madrid: Pirámide.

Asghari, Somayeh, Sahar Targholi, Ali Kazemi, Saeed Shahriyari, and Lila Rajabion. 2020. A new conceptual framework for identifying the factors influencing the effectiveness of competitive intelligence. Competitiveness Review 30: 555-76. [CrossRef]

Bao, Changhuo, Qingjiu Tao, and Luhong Dai. 1998. The developing Chinese competitive intelligence profession. Competitive Intelligence Review 9: 42-47. [CrossRef]

Bartes, František. 2014. Defining a Basis for the New Concept of Competitive Intelligence. Acta Universitatis Agriculturae et Silviculturae Mendelianae Brunensis 62: 1233-42. [CrossRef]

Begg, Maha, and Adeline Du Toit. 2007. Level of importance attached to competitive intelligence at a mass import-retail organization. South African Journal of Information Management 9. Available online: http://www.sajim.co.za (accessed on 27 January 2021). [CrossRef]

Bergeron, Pierrette, and Christine A. Hiller. 2002. Competitive intelligence. Annual Review of Information Science and Technology 36: 353-90. [CrossRef]

Berkowitz, Leonard. 1993. Getting the Most from Your Patents. Research Technology Management 36: 26-31. [CrossRef]

Bernhardt, Douglas. 1994. "I want it fast, factual, actionable"-Tailoring competitive intelligence to executives' needs. Long Range Planning 27: 12-24. [CrossRef]

Butterfield, Kenneth, Linda Trevin, and Gary Weaver. 2000. Moral Awareness in Business Organizations: Influences of Issue-Related and Social Context Factors. Human Relations 53: 981-1018. [CrossRef]

Calof, Jonathan, and Nisha Sewdass. 2020. On the relationship between competitive intelligence and innovation. Journal of Intelligence Studies in Business 10. [CrossRef]

Calof, Jonathan, and Sheila Wright. 2008. Competitive intelligence: A practitioner, academic and inter-disciplinary perspective. European Journal of Marketing 42: 717-30. [CrossRef]

Caseiro, Nuno, and Arnaldo Coelho. 2019. The influence of Business Intelligence capacity, network learning and innovativeness on startups performance. Journal of Innovation \& Knowledge 4: 139-45. [CrossRef]

Cavallo, Angelo, Silvia Sanasi, Antonio Ghezzi, and Andrea Rangone. 2020. Competitive intelligence and strategy formulation: connecting the dots. Competitiveness Review 31: 250-75. [CrossRef]

Chaki, Saumya. 2015. Enterprise Information Management in Practice: Managing Data and Leveraging Profits in Today's Complex Business Environment, 1st ed. Berkeley: Apress. [CrossRef]

Chevallier, Christine, Zouhair Laarraf, Jean Sébastien Lacam, Anthony Miloudi, and David Salvetat. 2016. Competitive intelligence, knowledge management and coopetition: The case of European high-technology firms. Business Process Management Journal 22: 1192-211. [CrossRef]

Colakoglu, Tanju. 2011. The Problematic of Competitive Intelligence: How to Evaluate\& Develop Competitive Intelligence? Procedia, Social and Behavioral Sciences 24: 1615-23. [CrossRef]

Correia, José Jonas Alves, Leandro Martins da Silva, Ramon Rodrigues dos Santos, Josete Florencio dos Santos, and Umbelina Cravo Teixeira Lagioia. 2019. Características da produção científica acerca do tema inteligência competitiva: uma análise bibliométrica. Ciência da informação 48. Available online: http:/ / revista.ibict.br/ciinf/article/view/4538/4288 (accessed on 8 June 2021).

De Pelsmacker, Patrick, Marie-Luce Muller, Wilma Viviers, Andrea Saayman, Ludo Cuyvers, and Marc Jegers. 2005. Competitive intelligence practices of South African and Belgian exporters. Marketing Intelligence E Planning 23: 606-20. [CrossRef]

Dishman, Paul, and Tim Pearson. 2003. Assessing intelligence as learning within an industrial marketing group: A pilot study. Industrial Marketing Management 32: 615-20. [CrossRef] 
do Prado, Anderson Evandro, and Campos Fernando Celso de. 2018. Analise bibliométrica 1990-2014: inteligência competitiva. Perspectivas em Ciência da Informação 23: 71-88. [CrossRef]

Du Toit, Adeline. 2015. Competitive intelligence research: An investigation of trends in the literature. Journal of Intelligence Studies in Business 5. [CrossRef]

Du Toit, Adeline, and Marié-Luce Muller. 2005. Training competitive intelligence analysts via the Web: the University of Johannesburg experience. Journal of Education for Library and Information Science 46: 320-32. [CrossRef]

Elbashir, Mohamed, Philip Collier, and Steve Sutton. 2011. The Role of Organizational Absorptive Capacity in Strategic Use of Business Intelligence to Support Integrated Management Control Systems. The Accounting Review 86: 155-84. [CrossRef]

Erickson, Scott, and Helen Rothberg. 2013. Intelligence in the oil path: knowledge management and competitive intelligence insight. Journal of Intelligence Studies in Business 3: 29-36. Available online: https://search.proquest.com/docview/1468445856?pqorigsite $=$ gscholar\&fromopenview $=$ true (accessed on 27 January 2021).

Fernández, Jesús Santiago. 2016. Situación de la Inteligencia Económica en España, Documento de trabajo 07/2016, en El Sistema de Inteligencia Económica en España del Centro Superior de Estudios de la Defensa Nacional. Instituto Español de Estudios Estratégicos. Madrid, España. Available online: http://www.spainglobal.com/files/Sistema_Inteligencia_Economica_Espana. pdf (accessed on 27 January 2021).

Fleisher, Craig S. 2001. An introduction to the management and practice of competitive intelligence (CI). In Managing Frontiers in CI. Edited by Craig S. Fleisher and David L. Blenkhor. Westport: Quorum Books, Available online: http://www.questia.com/PM. qst? G- $+\mathrm{d}=101031511$ (accessed on 27 January 2021).

Fleisher, Craig S. 2008. Using open source data in developing competitive and marketing intelligence. European Journal of Marketing 42: 852-66. [CrossRef]

Fleisher, Craig S., and David L. Blenkhorn, eds. 2003. Controversies in Competitive Intelligence: The Enduring Issues. Westport: Greenwood Publishing Group.

Fleisher, Craig S., and Babette Bensoussan. 2007. Business and Competitive Analysis: Effective Application of New and Classic Methods, 1st ed. Hoboken: Financial Times Prentice Hall.

Ghannay, Jihene Chebbi, and Zeineb Ben Ammar Mamlouk. 2012. Synergy Between Competitive Intelligence and Knowledge Management-A key for Competitive Advantage. Journal of Intelligence Studies in Business 2. [CrossRef]

González Cussac, José Luis. 2013. Inteligencia jurídica: El valor estratégico del derecho en la seguridad económica. Cuadernos de Estrategia 162: 103-34. Available online: https:/ / dialnet.unirioja.es/servlet/articulo?codigo=4275970 (accessed on 27 January 2021).

Gonzalvo, Vicente. 2015. Inteligencia Económica y Seguridad Nacional. Madrid: Dynkinsson.

Gordon, Steven, Monidepaa Tarafdar, Robert Cook, Richard Maksimoski, and Bernice Rogowitz. 2008. Improving the Front End of Innovation with Information Technology. Research Technology Management 51: 50-58. [CrossRef]

Gračanin, Šaban, Edin Kalac, and Dejan Jovanović. 2015. Competitive Intelligence: Importance and Application in Practice. Review of Innovation and Competitiveness 1: 25-44. [CrossRef]

Guimaraes, Tor, Ketan Paranjape, Mike Cornick, and Curtis Armstrong. 2018. Empirically Testing Factors Increasing Manufacturing Product Innovation Success. International Journal of Innovation and Technology Management 15: 1850019. [CrossRef]

Heinrichs, John, and Jeen-Su Lim. 2008. Impact of Marketing Model Application and Competitive Intelligence Utilization on Strategic Response Capability. Journal of Strategic Marketing 16: 91-110. [CrossRef]

Hitt, Michael, R. Duane Ireland, and Robert Hoskinsson. 2000. Case Notes for Strategic Management: Competitiveness and Globalization, 4th ed. New York: Cengage Learning.

Homburg, Christian, Sascha Alavi, Thomas Rajab, and Jan Wieseke. 2017. The contingent roles of R\&D-sales versus R\&D-marketing cooperation in new-product development of business-to-business firms. International Journal of Research in Marketing 34: 212-30. [CrossRef]

Hoppe, Magnus. 2013. The intelligence worker as a knowledge activist—An alternative view on intelligence by the use of Burke's pentad. Journal of Intelligence Studies in Business 3. [CrossRef]

Hughes, Douglas, Joel Le Bon, and Adam Rapp. 2013. Gaining and leveraging customer-based competitive intelligence: the pivotal role of social capital and salesperson adaptive selling skills. Journal of the Academy of Marketing Science 41: 91-110. [CrossRef]

Hughes, Stephanie. 2017. A new model for identifying emerging technologies. Journal of Intelligence Studies in Business 7. [CrossRef]

Juillet, Alain. 2012. Gérer les Risques Criminels en Enterprise: Stratégies et Comportements Practiques. Paris: Larcier Business.

Kahaner, Larry. 1996. Competitive Intelligence, 1st ed. New York: Simon and Schuster.

Kochen, Manfred. 1989. Management intelligence systems. Advances in Computers 28: 227-78. [CrossRef]

Kuester, Sabine, and Andreas Rauch. 2016. A job demands-resources perspective on salespersons' market intelligence activities in new product development. The Journal of Personal Selling \& Sales Management 36: 19-39. [CrossRef]

Kühn, M. L. 2012. Competitive Intelligence: The Key to Intelligent Business. Somerset-West: Mediator Printers.

Lesca, Nicolas, and Marie-Laurence Caron-Fasan. 2008. Strategic scanning project failure and abandonment factors: lessons learned. European Journal of Information Systems 17: 371-86. [CrossRef]

Leydesdorff, Loet, and Inga Ivanova. 2016. "Open innovation" and "triple helix" models of innovation: can synergy in innovation systems be measured? Journal of Open Innovation 2: 1-12. [CrossRef] 
Lichtenthaler, Eckhard. 2005. The choice of technology intelligence methods in multinationals: towards a contingency approach. International Journal of Technology Management 32: 388-407. [CrossRef]

López-Robles, José Ricardo, José Ramón Otegi-Olaso, Igone Porto Gómez, and Manuel J. Cobo. 2019a. 30 years of intelligence models in management and business: A bibliometric review. International Journal of Information Management 48: 22-38. [CrossRef]

López-Robles, José Ricardo, José Ramón Otegi-Olaso, Rubén Arcos, Nadia Karina Gamboa-Rosales, and Hamurabi Gamboa-Rosales. 2019b. Mapping the structure and evolution of JISIB: A bibliometric analysis of articles published in the Journal of Intelligence Studies in Business between 2011 and 2017. Journal of Intelligence Studies in Business 8. [CrossRef]

López-Robles, José Ricardo, José Ramón Otegi-Olaso, Igone Porto-Gomez, Hamurabi Gamboa-Rosales, and Nadia Karina GamboaRosales. 2020a. Understanding the intellectual structure and evolution of Competitive Intelligence: a bibliometric analysis from 1984 to 2017. Technology Analysis E Strategic Management 32: 604-19. [CrossRef]

López-Robles, José Ricardo, José Ramón Otegi-Olaso, Igone Porto-Gómez, Hamurabi Gamboa-Rosales, and Nadia Karina GamboaRosales. 2020b. The relationship between Business Intelligence and Competitive Intelligence: A retrospective analysis and literature review from 1959 to 2017. Revista Española de Documentación Científica 43: e256. [CrossRef]

Maguire, Stuart. 2010. The intelligence alchemy and the twenty-first century organization. Strategic Direction 26. [CrossRef]

McGonagle, John, and Carrolyn Vella. 1998. Protecting Your Company against Competitive Intelligence. Westport: Quorum Books.

Montgomery, David, and Charles Weinberg. 1979. Toward Strategic Intelligence Systems. Journal of Marketing 43: 41-52. [CrossRef]

Park, Hang Sik. 2017. Technology convergence, open innovation, and dynamic economy. Journal of Open Innovation 3: 1-13. [CrossRef]

Pellissier, Rene, and Tshilidzi Nenzhelele. 2013. Towards a universal definition of competitive intelligence. South African Journal of Information Management 15. [CrossRef]

Porter, Michael Eugene. 1980. Competitive Strategy: Techniques of Analyzing Industries and Competitors. New York: The Free Press.

Powell, John Hamer, and John Peter Bradford. 2000. Targeting intelligence gathering in a dynamic competitive environment. International Journal of Information Management 20: 181-95. [CrossRef]

Qiu, Tianjiao. 2008. Scanning for competitive intelligence: A managerial perspective. European Journal of Marketing 42: 814-35. [CrossRef]

Ramaseshan, B., Asmai Ishak, and Russel Kingshott. 2013. Interactive effects of marketing strategy formulation and implementation upon firm performance. Journal of Marketing Management 29: 1224-50. [CrossRef]

Rohrbeck, René, and Hans Georg Gemünden. 2011. Corporate foresight: Its three roles in enhancing the innovation capacity of a firm. Technological Forecasting \& Social Change 78: 231-43. [CrossRef]

Rothberg, Helen, and Scott Erickson. 2017. Big data systems: knowledge transfer or intelligence insights? Journal of Knowledge Management 21: 92-112. [CrossRef]

Rouach, Daniel, and Patrice Santi. 2001. Competitive intelligence adds value:-Five intelligence attitudes. European Management Journal 19: 552-59. [CrossRef]

Rouibah, Kamei, and Samia Ould-Ali. 2002. PUZZLE: A concept and prototype for linking business intelligence to business strategy. The Journal of Strategic Information Systems 11: 133-52. [CrossRef]

Sánchez, Luis. 2015. La toma de decisiones en la empresa ante la incertidumbre política. El papel de la Inteligencia Económica/Empresarial. Papeles de Liderazgo 8: 1-9. Available online: https:/ / masconsulting.es/blog/2015/09/08/papeles-deliderazgo-n8-la-toma-de-decisiones-en-la-empresa-ante-la-incertidumbre-politica/ (accessed on 5 February 2021).

Schultze, Ulrike, and Richard Boland. 2000. Knowledge management technology and the reproduction of knowledge work practices. The Journal of Strategic Information Systems 9: 193-212. [CrossRef]

Schwarz, Jan Oliver. 2007. Competitive Intelligence: A Field for Futurists? Futures Research Quarterly 23: 55.

Sewdass, Nisha. 2012. Proposing a competitive intelligence (CI) framework for Public Service departments to enhance service delivery. South African Journal of Information Management 14: e1-e13. [CrossRef]

Shujahat, Muhammad, Saddam Hussain, Sammar Javed, Muhammad Imran Malik, Ramayah Thurasamy, and Junaid Ali. 2017. Strategic management model with lens of knowledge management and competitive intelligence: A review approach. VINE Journal of Information and Knowledge Management Systems 47: 55-93. [CrossRef]

Sun, Tzu. 1988. The Art of War. Oxford: Oxford University Press.

Tahmasebifard, Hamid. 2018. The role of competitive intelligence and its sub-types on achieving market performance. Cogent Business $\mathcal{E}$ Management 5: 1540073. [CrossRef]

Talaoui, Yassine, and Marko Kohtamäki. 2020. Of BI research: A tale of two communities. Management Research Review 43: 1371-94. [CrossRef]

Tanev, Stoyan, and Tony Bailetti. 2008. Competitive intelligence information and innovation in small Canadian firms. European Journal of Marketing 42: 786-803. [CrossRef]

Tao, Qingiu, and John E. Prescott. 2000. China: Competitive intelligence practices in an emerging market environment. Competitive Intelligence Review 11: 65-78. [CrossRef]

Tarek, Bel Hadj, Mghri Zouhayer, and Ghodbane Adel. 2019. Entrepreneurial Competitive Intelligence between Uppsala Model and Born Global Theories in the Case of North African SMEs. Journal of the Knowledge Economy 10: 734-55. [CrossRef]

Tarek, Bel Hadj, Ghodbane Adel, and Aouadi Sami. 2016. The relationship between "competitive intelligence" and the internationalization of North African SMEs. Competition E Change 20: 326-36. [CrossRef] 
Teixeira, Renata Cristina, and Souza Cristina. 2017. Evolução da inteligência competitiva com base em estudo métrico de sua literatura. Perspectivas em Ciência da Informação 22: 170-85. [CrossRef]

Tej Adidam, Phani Tej, Sampara Gajre, and Shubhra Kejriwal. 2009. Cross-cultural competitive intelligence strategies. Marketing Intelligence E Planning 27: 666-80. [CrossRef]

Tej Adidam, Phani Tej, Madhumita Banerjee, and Paurav Shukla. 2012. Competitive intelligence and firm's performance in emerging markets: an exploratory study in India. The Journal of Business $\mathcal{E}$ Industrial Marketing 27: 242-54. [CrossRef]

Teo, Thompson, and Wing Yee Choo. 2001. Assessing the impact of using the Internet for competitive intelligence. Information $\mathcal{E}$ Management 39: 67-83. [CrossRef]

Trong Tuan, Luu. 2013. Leading to learning and competitive intelligence. The Learning Organization 20: 216-39. [CrossRef]

Tuan, Luu Trong. 2016. Organisational ambidexterity and supply chain agility: the mediating role of external knowledge sharing and moderating role of competitive intelligence. International Journal of Logistics 19: 583-603. [CrossRef]

Ulrike Schultze. 2000. A Confessional Account of an Ethnography about Knowledge Work. MIS Quarterly 24: 3-41. [CrossRef]

Veugelers, Mark, Jo Bury, and Stijn Viaene. 2010. Linking technology intelligence to open innovation. Technological Forecasting $\mathcal{E}$ Social Change 77: 335-43. [CrossRef]

Viviers, Wilma, Andrea Saayman, and Marié-Luce Muller. 2005. Enhancing a competitive intelligence culture in South Africa. International Journal of Social Economics 32: 576-89. [CrossRef]

Vriens, Dirk, and Klaus Solberg Søilen. 2014. Disruptive Intelligence-How to gather Information to deal with disruptive innovations. Journal of Intelligence Studies in Business 4: 63-78. [CrossRef]

Vroman, H. William. 1995. Product Juggernauts: How Companies Mobilize to Generate a Stream of Market. Academy of Management Perspectives 9: 87-89. [CrossRef]

Walker, Thomas D. 1994. The literature of competitive intelligence. Library Trends 43: 271-84. Available online: https://www.ideals. illinois.edu/bitstream/handle/2142/7958/librarytrendsv43i2i_opt.pdf?sequence=1 (accessed on 5 February 2021).

Watts, Robert J., and Alan Porter. 1997. Innovation forecasting. Technological Forecasting $\mathcal{E}$ Social Change 56: 25-47. [CrossRef]

Web of Science. 2021. Fundación Española para la Ciencia y la Tecnología FEYCT. Available online: https://www.recursoscientificos. fecyt.es/ (accessed on 27 January 2021).

West, Chris. 1999. Competitive Intelligence in Europe. Business Information Review 16: 143-50. [CrossRef]

Wright, Sheila, and Johnatan Calof. 2006. The quest for competitive, business and marketing intelligence: A country comparison of current practices. European Journal of Marketing 40: 453-65. [CrossRef]

Xu, Kaiquan, Stephen Liao, Jiexun Li, and Yuxia Song. 2011. Mining comparative opinions from customer reviews for Competitive Intelligence. Decision Support Systems 50: 743-54. [CrossRef]

Zangoueinezhad, Abouzar, and Asghar Moshabaki. 2009. The role of structural capital on competitive intelligence. Industrial Management and Data Systems 109: 262-80. [CrossRef]

Zinkhan, George, and Betsy Gelb. 1985. Competitive intelligence practices of industrial marketers. Industrial Marketing Management 14: 269-75. [CrossRef] 